\title{
HPV vaccination: a Tunisian challenge
}

\author{
Mohamed Aymen Ferjaoui (1D), Tunis 1007, Tunisia
}

Tunisia is a North African country, a real bridge between Europe and Africa. Its population is approximately 11.5 million. In Tunisia, the incidence of cervical cancer is 4.1/100 000 women, and 300 new cases are diagnosed per year with $75 \%$ of these as advanced cervical cancer. It is the third gynecological cancer (including breast) and the second pelvic cancer after endometrial cancer. Systematic mass Papanicolaou (Pap) smear screening does not exist and it is done individually in public hospitals and private clinics. The coverage of Pap smear screening is low and does not exceed $17 \%$ of all Tunisian women, with inter-regional inequalities. In the interior regions of the country Tunisian women can miss their screening.

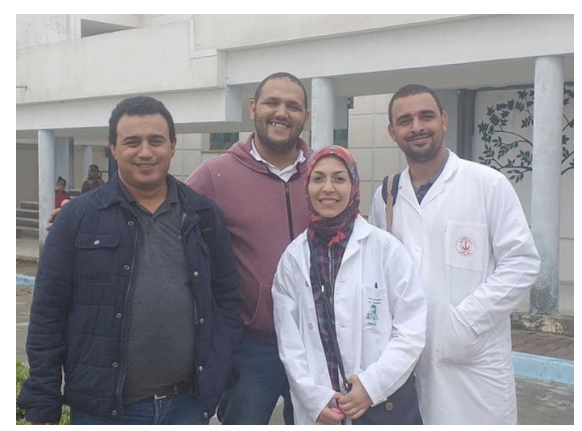

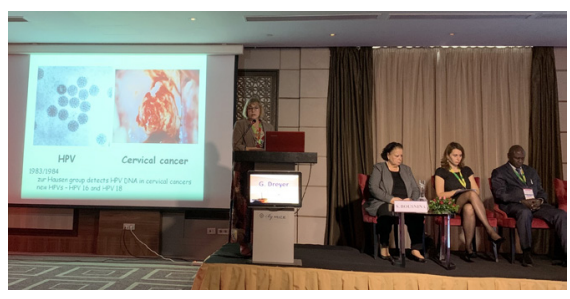

The Tunisian Society of Gynecology and Obstetrics (STGO) periodically organizes several campaigns for cervical cancer screening throughout the Tunisian territory. These events involve gynecological surgeons and fellows in gynecology and obstetrics. Cases where cervical disease is detected are managed in university departments of gynecology and obstetrics. STGO is also working to promote and introduce human papillomavirus (HPV) vaccination in the Tunisian vaccination calendar. Several meetings have been organized with the various stakeholders.

Vaccination coverage in Tunisia is approximately $97 \%$ and the schooling rate is $98 \%$, thus allowing for generalized HPV vaccination. The biggest event was held on October 31 to November 2, 2019-the national STGO meeting - at which there was a special session advocating for HPV vaccination. Three major topics were presented: the interest of HPV vaccination,
HPV vaccination in Africa, and the challenge of Tunisian gynecologists to introduce this vaccination to protect Tunisians. The official procedure is in an advanced phase and Tunisian gynecologists have received serious promises to make this dream come true.

Correspondence to Dr Mohamed Aymen Ferjaoui, B of Gynecologic Oncology, Gynecologic Surgery and Obstetric, Tunis Maternity Center, Tunis 1007, Tunisia; ferjaoui16@yahoo.fr

Contributors I'm the only author of this work.

Funding The authors have not declared a specific grant for this research from any funding agency in the public, commercial or not-for-profit sectors.

Competing interests None declared.

Patient consent for publication Not required.

Provenance and peer review Not commissioned; externally peer reviewed.

(C) IGCS and ESGO 2020. No commercial re-use. See rights and permissions. Published by BMJ.

\section{Check for updates}

To cite Ferjaoui MA. Int J Gynecol Cancer 2020;30:1248.

Accepted 19 November 2019

Published Online First 23 April 2020

Int J Gynecol Cancer 2020;30:1248.

doi:10.1136/ijgc-2019-001076

ORCID iD

Mohamed Aymen Ferjaoui http://orcid.org/00000002-3132-7343 